\title{
The seat belt law and after
}

\author{
M D COLE,' L CLEARKIN, ${ }^{2}$ T DABBS, ${ }^{3}$ AND D SMERDON ${ }^{4}$ \\ From 'Manchester Royal Eye Hospital, ${ }^{2}$ St Paul's Eye Hospital, Liverpool, ${ }^{3}$ Royal Hallamshire Hospital, \\ Sheffield, and ${ }^{4}$ Birmingham and Midland Eye Hospital
}

SUMMARY We report a retrospective study of 378 perforating eye injuries presenting between August 1981 and July 1984 to four major teaching hospitals. The aetiological groups have been analysed together and by region, and preventive measures for some groups are discussed. We have confirmed the effectiveness of seat belt legislation in reducing serious eye injury.

It is important to monitor the aetiology of serious eye injuries. Only then will a pattern emerge which may allow recognition of preventable eye disease. Proper action may then be taken to reduce the incidence of such injuries.

This multicentre study reviewed the aetiology of perforating eye injuries 18 months before and after the introduction of seat belt legislation. There were two objectives; firstly, to see whether the reduction in injury from road traffic accidents (RTAs) shown in Hampshire' was similar in other regions of the UK, and secondly to assess the present aetiological pattern of perforating injury so that future preventive measures can be considered.

\section{Materials and methods}

Four ophthalmological units participated in the study: Manchester Royal Eye Hospital, St Paul's Eye Hospital, Liverpool, the Eye Department of the Royal Hallamshire Hospital, Sheffield, and the Birmingham and Midland Eye Hospital. These centres were chosen because each was the major referral centre for their respective region. Each served industrial and urban communities, and could be expected to receive both motorway and urban RTA referrals.

The theatre registers were used to identify all cases of penetrating eye injury between 1 August 1981 and 31 July 1984 . The corresponding medical records were examined. The following parameters were recorded: date of injury, age, sex, detailed aetiological history, details of injury.

The cases were divided into two 18-month periods by their date of injury. Period A was from 1 August

Correspondence to M D Cole, FRCS, Birmingham and Midland Eye Hospital, Church Street, Birmingham B3 2NS.
1981 to 31 January 1983, while period B was from 1 February 1983 to 31 July 1984 . These represented two equal intervals before and after seat belt legislation.

Each period was then broken down by region and into one of seven aetiological groups as follows: RTA, assault, sporting, occupational, domestic, childhood play, unknown. In the RTA group we recorded both the position of the patient in the vehicle and whether or not a seat belt was worn (if the information was available). An occupational injury was one which occurred at work and as a direct consequence of work. Thus a hammer and chisel injury occurring at home was not included in this group. An injury occurring below the age of 14 (and not an RTA) was classified as childhood play regardless of cause.

\section{Results}

The records of 381 perforating eye injuries were reviewed. This figure represented an $83 \%$ retrieval. Three of these cases were excluded from analysis because of insufficient recorded information. The results are outlined in Tables 1 to 9 .

The overall aetiological pattern of injuries by region is summarised in Table 1 . The only significant differences between periods A and B were found in the RTA group. The incidence of RTAs as a cause of perforating eye injury fell from $17 \cdot 1 \%$ (39) to $6 \%$ (9) after seat belt legislation. Assaults accounted for $11.1 \%$ of all perforating injuries. A regional variation was noted (Manchester 13.4\%, Liverpool $13 \cdot 1 \%$, Sheffield $11 \cdot 7 \%$, and Birmingham $7 \cdot 7 \%$ ), though this trend is not statistically significant $\left(\chi^{2}\right.$ test with Yates's correction).

A regional variation was also demonstrated in the 
Table 1 Aetiology by region and time period

\begin{tabular}{|c|c|c|c|c|c|c|c|c|c|c|c|c|}
\hline & \multicolumn{5}{|c|}{ Period A } & \multicolumn{5}{|c|}{ Period B } & \multirow[t]{2}{*}{ Total } & \multirow[t]{2}{*}{$\%$} \\
\hline & $M$ & $L$ & $S$ & $B$ & $S T$ & $M$ & $L$ & $S$ & $B$ & $S T$ & & \\
\hline RTAs & 11 & 9 & 2 & 17 & 39 & 1 & 1 & 1 & 6 & 9 & 48 & $12 \cdot 7$ \\
\hline Assault & 8 & 5 & 6 & 4 & 23 & 9 & 3 & 1 & 6 & 19 & 42 & $11 \cdot 1$ \\
\hline Sport & 4 & 1 & 1 & 5 & 11 & 1 & 1 & 1 & 5 & 8 & 19 & $5 \cdot 0$ \\
\hline Domestic & 25 & 4 & 7 & 9 & 45 & 17 & 3 & 6 & 7 & 33 & 78 & $20 \cdot 6$ \\
\hline Childhood & 17 & 9 & 5 & 19 & 50 & 12 & 4 & 4 & 11 & 31 & 81 & $21 \cdot 4$ \\
\hline Occupational & 11 & 13 & 12 & 22 & 58 & 10 & 8 & 14 & 17 & 49 & 107 & $28 \cdot 3$ \\
\hline Unknown & 1 & 0 & 0 & 1 & 2 & 1 & 0 & 0 & 0 & 1 & 3 & 0.8 \\
\hline
\end{tabular}

ST = subtotal. $\mathrm{M}=$ Manchester. $\mathrm{L}=$ Liverpool. $\mathrm{S}=$ Sheffield. $\mathrm{B}=$ Birmingham.

Table 2 Ageratios

\begin{tabular}{|c|c|c|c|c|c|c|c|c|c|}
\hline & \multicolumn{8}{|c|}{ Agegroups } & \multirow[t]{2}{*}{$M / F$} \\
\hline & $0-9$ & $10-19$ & $20-29$ & $30-39$ & $40-49$ & $50-59$ & $60-69$ & $>70$ & \\
\hline RTAs & 2 & 8 & 25 & 6 & 3 & 2 & 1 & 1 & $39: 9$ \\
\hline Assault & - & 13 & 13 & 2 & 4 & 6 & 2 & 2 & $39: 3$ \\
\hline Sport & - & 5 & 8 & 5 & 1 & 0 & 0 & 0 & $19: 0$ \\
\hline Domestic & - & 18 & 20 & 13 & 9 & 5 & 7 & 6 & $67: 11$ \\
\hline Childhood & 49 & 32 & - & - & - & - & - & - & $63: 11$ \\
\hline Occupational & - & 18 & 29 & 26 & 24 & 8 & 1 & 1 & $105: 2$ \\
\hline Totals & 51 & 94 & 95 & 52 & 41 & 21 & 11 & 10 & $332: 36$ \\
\hline Percentage & $13 \cdot 4$ & $24 \cdot 8$ & $25 \cdot 1$ & $13 \cdot 8$ & $10 \cdot 8$ & $5 \cdot 5$ & $2 \cdot 9$ & $2 \cdot 6$ & \\
\hline
\end{tabular}

$\mathrm{M} / \mathrm{F}=$ ratio of male to females. $-=$ Incompatible, see text.

occupational group, which accounted for $28.3 \%$ of perforating eye injuries (Manchester 16.5\%, Liverpool $34.4 \%$, Sheffield $43.3 \%$, and Birmingham $30 \%)$. The differences in the figures between Manchester and each of the other centres are statistically significant by the $\chi^{2}$ test with Yates's

Table 3 Position of injured person in car

Driver

Front seat passenger

Back seat passenger

Unspecified

Table 4 Seat belt status

\begin{tabular}{lclc}
\hline & Period A & Period B & Total \\
\hline Wearing & 2 & 3 & 5 \\
Not wearing & 27 & 4 & 31 \\
No history obtained & 10 & 1 & 11 \\
Wearing but not fastened & 0 & 1 & 1 \\
\hline
\end{tabular}

Table 5 Assault cases-detailed aetiology

\begin{tabular}{lrll}
\hline Broken glass & 18 & Gun & 2 \\
Broken bottle & 3 & Carpet pin & 1 \\
Knife & 4 & Chain & 1 \\
Fist & 4 & Pen & 1 \\
Thumbs & 3 & Karate kick & 1 \\
Stone & 2 & Unknown & 4 \\
Pub brawl & 2 & & \\
\hline
\end{tabular}

correction (Manchester and Sheffield $p<0.01$, Manchester and Liverpool $p<0.025$, Manchester and Birmingham $\mathrm{p}<0 \cdot 05$ ).

In Table 2 the aetiological groups have been broken down by age and sex. As expected the majority of injuries occurred between the ages of 14 and 40 . There was an overall male preponderance of $7 \cdot 8: 1$, which was particularly striking in the sport, occupational, and assault groups.

Table 3 shows the position of the patient in the car. There were more injuries involving the front seat passenger than the driver (26 against 14). There were only three back seat passenger injuries. Table 4 shows the seat belt status. This was recorded in 37 out of the 48 cases. Thirty one of those 37 cases were not wearing a seat belt. One patient was wearing the seat belt without its being fastened.

Table 5 itemises the weapons used in the assault cases: $50 \%$ were caused by a broken glass or bottle.

Table 6 is an analysis of the sporting injuries and shows the frequent association with spectacle breakage (seven out of 17).

The causes of occupational and domestic injuries are given in Tables 7 and 8 . There were 30 recorded injuries occurring when a hammer and chisel were being used ( 23 out of 107 occupational and 7 out of 78 domestic).

Childhood injuries are broken down by cause in Table 9. Of the 81 injuries 11 were caused by a dart. 
Table 6 Sporting injuries

\begin{tabular}{llllll}
\hline Pursuit & No. & Gls & Pursuit & No. & Gls \\
\hline Darts & 4 & 0 & Fishing & 2 & 0 \\
Squash & 5 & 5 & Hurling & 1 & 0 \\
Shooting & 4 & 0 & Cricket & 1 & 1 \\
Golf & 2 & 1 & & & \\
\hline
\end{tabular}

Gls denotes number of injuries caused by broken spectacles.

Table 7 Industrial injuries

\begin{tabular}{ll}
\hline Using hammer & 43 (23 using a chisel) \\
Operating machine & 15 \\
Using: screwdriver & 5 \\
knife & 5 \\
wire & 4 \\
drill & 3 \\
nail punch & 2 \\
Grit/stone/coal & 4 \\
Miscellaneous & 28 \\
\hline
\end{tabular}

In four of these cases the injury was caused by the flight end entering the eye.

\section{Discussion}

Although all eye injuries should be preventable, attempting to reduce their incidence is fraught with problems. ${ }^{2}$ Factors which can affect the pattern of eye injuries include changes in both population and environment. Preventive measures taken are influenced by social conscience as well as economic considerations. $^{3}$

The age and sex distributions showed a similar pattern to those of previous series. ${ }^{+6}$ We found a lower percentage of eye injuries in the under 9 age group (Table 2). The male preponderance was greater in this series $(7 \cdot 8: 1)$ than in Eagling's $s$ study $(3 \cdot 5: 1)$.

There were six cases of endophthalmitis $(1 \cdot 6 \%)$. Five of these were excised and one was retained, albeit with no perception of light. Two cases of endophthalmitis were associated with intraocular steel foreign bodies from hammering. Although these injuries are thought to be sterile, all possible precautions to prevent intraocular infection should still be taken.

There was one recorded case of sympathetic ophthalmitis. It occurred in a child who had injured her eye (scleral perforation with uveal prolapse) with a pair of compasses two weeks prior to presentation.

ROAD TRAFFIC ACCIDENTS

In all four regions the reduction in injury due to RTAs before and after the seat belt law was demon-
Table 8 Domestic injuries

\begin{tabular}{ll}
\hline DIY & $29(13$ IOFBs, 7 hammer and chisel $)$ \\
Fall & $14(1$ faint and 1 fit $)$ \\
Glass & 13 (5 exploding bottles $)$ \\
Car/bike repairs & 6 \\
Blunt injury & 4 (stone/brick $)$ \\
Gardening & 2 \\
Home brewing & 2 \\
Miscellaneous & \\
Dog bite & 1 \\
Pen & 1 \\
Knife & 1 \\
Record & 1 \\
Plate & 1 \\
Fingernail & 1 \\
Unknown & 1 \\
Walking on rubbish tip & 1 \\
\hline
\end{tabular}

DIY $=$ 'do it yourself' domestic repairs.

IOFB = intraocular foreign body.

Table 9 Childhood injuries

\begin{tabular}{ll}
\hline Dart & 11 \\
Blunt objects & 8 (stone, brick, football, hecl, knee) \\
Knife & 8 \\
Pen/pencil & 7 \\
Wood/stick & 7 \\
Glass/bottle/cup & 5 \\
Plastic fragment & 4 \\
Hammering & 4 (chisel, brick, bullet, cartridge) \\
Air gun & 3 \\
Garden (bushes, etc) & 3 \\
Wire & 2 \\
Pliers/tweezers & 2 \\
Bicycle repair & 2 \\
Ruler/measure & 2 \\
Spike/nail & 2 \\
Exploding bottle & 1 \\
Spotlight & 1 \\
Chisel & 1 \\
Stitch cutter & 1 \\
Swimming goggles & 1 \\
Fish hook & 1 \\
Napkin pin & 1 \\
Compasses & 1 \\
\hline
\end{tabular}

strated clearly. Initially it was puzzling why Sheffield should have so few RTA cases, but Rotherham and Chesterfield Hospitals are closer to the motorway network, and this influenced Sheffield's intake of them. The reduction in RTA-induced perforating eye injuries after the seat belt law in Hampshire was analysed by Hall.' We have confirmed that his conclusions are widespread and consistent. The estimated annual incidence has decreased by $76.9 \%$ and is comparable to the figure obtained in the Hampshire study $(73 \%)$ RTAs predominantly affected the young. The number of working days lost, the cost to the NHS, and the cost in terms of visual handicap have been reviewed elsewhere.? There were four cases of double perforations in the series, of which two were due to RTAs. This is to be 
expected in view of the head trajectory through a windscreen. ${ }^{7}$

In this series the position of the injured patient in the motor vehicle was reviewed. Front seat passengers were more commonly affected than back seat. The driver has a moral responsibility for the safety of his passengers, and it may still be important to publicise this. We found the incidence of eye injury in back seat passengers to be very low. One of the three cases resulted from flying glass. It is not known how the other two suffered their injuries. In our opinion these figures hardly justify encouraging the introduction of seat belt legislation for back seat passengers.

Out of the 37 cases in which a clear history was obtained 31 admitted that they were not wearing their seat belts. One patient who was wearing a seat belt thought that it may not have been fastened. If these histories are correct, the wearing of a seat belt does not provide complete protection from eye injury. For example, in one instance the accident was so severe that the roof of the car was ripped off completely. In another case the belt apparently caused the patient's glasses to smash and perforate the eye, which seems hard to believe unless the belt was worn incorrectly. Despite imposition of the law, RTA-induced perforating eye injuries still occur. We must continue to encourage the wearing of seat belts.

\section{ASSAULT CASES}

We recorded a higher ratio and number of assault cases than in Roper-Hall's series ${ }^{4}$ in the 1950 s $(11 \cdot 1 \%$ against $0.75 \%$ ). Birmingham was not thought to be a violent city, but even so its incidence of assault in this study was $7 \cdot 7 \%$. Liverpool (13.1\%) and Manchester $(13.4 \%)$ had a higher incidence of assault cases and may reflect more unsettled social environments.

We discovered that 22 cases were of patients injured by a broken glass or bottle in or near a pub or club. The problem of glass breakage has been the subject of research for many years. ${ }^{8}$ Not only are we a long way from obtaining an unbreakable glass technically, but toughened glass of any kind is much more expensive and not yet cost effective. For large sporting occasions, plastic and paper have been used in place of the traditional drinking glass. There are no signs of this becoming more widely acceptable to the general public.

It should be possible to identify those pubs and clubs with a high incidence of glass injuries. However, the idea of imposing restrictions in the use of glass in these establishments was not met with enthusiasm by the Health and Safety Committee for the Brewers' Society (personal communication). They regard acts of such a malicious nature as being beyond their responsibility and out of their control.
The tougher penalties recently imposed by the courts of law are welcomed.

\section{SPORTING INJURIES}

The most common sport associated with penetrating eye injury was squash racquets. Despite attempts to encourage the use of plastic lenses or contact lenses in sportsmen and women, all five of our squash related injuries resulted from the wearing of glasses which shattered on impact. Sports clubs could help to reduce the incidence by introducing rules forbidding the use of glass spectacle lenses.

\section{OCCUPATIONAL INJURIES}

Hammer and chisel injuries were found to be most common. Fifteen machine operators suffered perforating injuries. The difficulty in encouraging the use of protective goggles has been discussed. ${ }^{2}$ Manchester had a much lower incidence of industrial injuries than the other centres, particularly Sheffield. This may be related to the type of industry prominent in each region.

\section{DOMESTIC INJURIES}

Thirteen cases in the DIY subgroup were due to hammering (mostly with chisels). There was only one case resulting from chopping wood, an occupation previously common, with a traditionally high ocular morbidity. ${ }^{2}$ Four cases were caused by exploding bottles; this subject has been reviewed elsewhere. ${ }^{9}$ Apart from these, no notable subgroups emerged.

\section{CHILDHOOD INJURIES}

Dart injuries are the largest subgroup. The most common mode of injury described was the flight end entering the eye while the player was pulling the dart out of the board (five cases). Four cases were associated with the dart bouncing off the board. The severity of these injuries could be minimised by altering the design of both dart and board. Parents should be made aware of their potential dangers.

Educational programmes on the prevention of accidents in the home have been used in the past and should be encouraged. Apart from the dart subgroup, the wide variety of objects responsible makes it difficult to pinpoint a group on which a publicity campaign could concentrate.

\section{CONCLUSION}

This study has confirmed the effectiveness of the seat belt law as a preventive measure in reducing serious ocular morbidity. Assault cases are becoming more frequent. They are caused most commonly by a broken glass or bottle. Although these injuries could be reduced by replacing drinking glasses with plastic or paper, this seems impracticable. Using plastic 
lenses in spectacles would reduce the number of sporting injuries. Dart injuries in children are common, and parents should be encouraged to show caution with darts in the home. We must continue to review eye trauma to identify repeated patterns of injury. These may then be influenced by justifiable and acceptable legislation or increasing public awareness.

We thank Miss E M Eagling, Miss E E Kritzinger, Mr A R Elkington, Mr M J Gilkes, and Dr P Dodson for their kind help and advice in the preparation of this paper.

\section{References}

1 Hall NF, Denning AM, Elkington AR, Cooper PJ. The eye and the seat belt in Wessex. BrJ Ophthalmol 1985; 69: 317-9.

2 Gilkes M. Prevention of eye injury. In: Tengroth BM, ed.
Proceedings of the Second World Congress of Ergophthalmology. Stockholm: Ergo-ophthalmology Society, 1978, 291-301.

3 Roper-Hall MJ. The changing pattern of injury. In: Tengroth BM, ed. Proceedings of the Second World Congress of Ergophthalmology Stockholm: Ergo-ophthalmology Society, 1978, 225-9.

4 Roper-Hall MJ. Treatment of ocular injuries. Trans Ophthalmol Soc UK 1959; 79: 57-69.

5 Johnson S. Perforating eye injuries: a five year study. Trans Ophthalmol Soc UK 1971; 91: 895-921.

6 Eagling EM. Perforating injuries of the eye. Br J Ophthalmol 1976; 60: 732-6.

7 Keightley SJ. Serious eye injury from windscreen contact. $J R$ Soc Med 1983; 76: 911-6.

8 Feldman O. Packaging in glass: how close are we to the unbreakable glass container? Read at the 12th National Conference of the Institute of Packaging, Stratford-upon-Avon, November 1977.

9 Al Salem M, Sheriff SM. Ocular injuries from carbonated soft drink bottle explosions. Br J Ophthalmol 1984; 68: 281-3.

Accepted for publication 29 July 1986. 